\title{
Estimating hurricane hazards using a GIS system
}

\author{
A. Taramelli ${ }^{1,5}$, L. Melelli ${ }^{2}$, M. Pasqui ${ }^{3}$, and A. Sorichetta ${ }^{4}$ \\ ${ }^{1}$ Lamont Doherty Earth Observatory of Columbia University, New York, Route 9W, Palisades, NY 10964, USA \\ ${ }^{2}$ Dipartimento di Scienze della Terra, Università degli Studi di Perugia, Perugia, Italy \\ ${ }^{3}$ Institute of Biometeorology - National Research Council, Firenze, Italy \\ ${ }^{4}$ Dipartimento di Scienze della Terra "Ardito Desio", Università degli Studi di Milano, Milano, Italy \\ ${ }^{5}$ ICRAM - Marine Sciences Research Institute, via di Casalotti, 300, Rome, Italy
}

Received: 13 February 2008 - Revised: 9 June 2008 - Accepted: 24 June 2008 - Published: 11 August 2008

\begin{abstract}
This paper develops a GIS-based integrated approach to the Multi-Hazard model method, with reference to hurricanes. This approach has three components: data integration, hazard assessment and score calculation to estimate elements at risk such as affected area and affected population. First, spatial data integration issues within a GIS environment, such as geographical scales and data models, are addressed. Particularly, the integration of physical parameters and population data is achieved linking remotely sensed data with a high resolution population distribution in GIS. In order to assess the number of affected people, involving heterogeneous data sources, the selection of spatial analysis units is basic. Second, specific multi-hazard tasks, such as hazard behaviour simulation and elements at risk assessment, are composed in order to understand complex hazard and provide support for decision making. Finally, the paper concludes that the integrated approach herein presented can be used to assist emergency management of hurricane consequences, in theory and in practice.
\end{abstract}

\section{Introduction}

Natural hazards include events such as earthquakes, floods, cyclones, droughts, tornadoes, landslides, hurricanes and tsunamis (San Miguel-Ayanz et al., 2000; Melelli and Taramelli, 2004; McInnes, 2006). As complex physical phenomena they are represented by nonlinear differential equations that can be linearized for the purpose of stability analysis of a system (Taylor, 1950; Emmons et al., 2006). Basically, the exponential function representing a natural environment could increase infinitely so that it would lead to an hazard situation (Scheidegger, 1994). A main issue is that

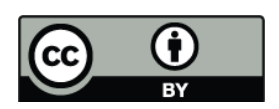

Correspondence to: A. Taramelli (ataram@ldeo.columbia.edu) the linearization holds true only for short time ranges so that an unstable state does not necessarily lead to a catastrophe. The growth process, in fact, could come to a stop when a saturation stage is reached so that the hazard event could vary greatly in magnitude and frequency. In this context one of the main question is that the apparent increase in frequency of natural disaster must be supported by an observation period much longer than a century (Alcantara-Ayala, 2002; Alexander, 2006) while the consistent reporting of most disaster types has a much shorter history. Monitoring techniques, measurement scales (e.g. Richter, Beaufort), and communications have only recently allowed the global reporting of hazard events in comparable terms (McInnes et al., 2000).

In recognition of this weak understanding in the multihazard research (Klein et al., 2004; Bell and Tobin, 2007), it was often addressed that it is necessary a considerable improvement of expertise in process studies and in mapping of precursor and antecedent conditions of natural phenomena (Hayden et al., 2007; Pender and Neelz, 2007). In particular we need important understanding improvement of magnitude and frequency concepts applied to the earth science. The multi-hazard research development has then always called for better application of current information technologies such as Geographical Information Systems (GIS) and Remote Sensing in natural hazards reduction (Alcantara-Ayala, 2002; Zerger, 2002; Zenger and Smith, 2003). Using GIS and remote sensing for understanding the complex natural hazards in spatial and temporal contexts is vital (Sorensen, 2000; Zerger et al., 2003). While satellite remote sensing has become a routine tool for land surface classification and mapping (Bocco et al., 2001; van Lynden and Mantel, 2001), the more recent fusion of these methods with GIS marked a catalytic change in our approach to geographic data collection (Burrough, 2001; Sanyal and Lu, 2004; Yuan, 2005). The role of remote sensing has increased both in the frequency of its use and in its influence upon the monitoring of large natural hazard events (Saito et al., 2004; Stramondo et al., 2007).

Published by Copernicus Publications on behalf of the European Geosciences Union. 
A growing number of studies have successfully utilized remote sensing to monitor earth process activity, and subsequently have concentrated on large scale investigations of hazard areas providing hazard zoning maps, or processing studies to assist in structural mitigation (Carson and Arthur, 2000; Taramelli and Melelli, 2008).

In the last decade, developing hazards models for hurricane impact using GIS and remote sensed data has then become a major topic of research (Colby et al., 2000; GuzmanTapia et al., 2005; Taramelli and Melelli, 2007). Basic approach based on Multi-Hazard model method has applied to hurricane hazard/elements at risk assessment using GIS data (Boyd et al., 2002; Applied Research Associates, 20032006 ${ }^{1}$; Bauch, 2003). Nevertheless, some unsolved questions are still under discussion. Indeed, despite the disastrous effects of hurricanes on coastal and inland communities are well known (O'Hare, 2001; Pielke et al., 2003; Watson and Johnson, 2005), there is still a need to better understand the hazard contributions of the different mechanisms related to hurricanes strike like storm surge, floods, and high winds. However hurricane hazards areal identification and prediction of their risk assessment remain largely unsolved problems (Kok and Winograd, 2002). It is well known that hurricane hazard is controlled by or dependent on a large and complex set of natural and human induced environmental factors (Howard et al., 2003; Shen et al., 2005; Pielke et al., 2008). Moreover, each type of the different events related to hurricane is dependent on a specific set of mechanisms and processes which are usually investigated by different kinds of expert. To complicate matters further, hurricane related events like storm surge, floods and high winds, requires forecasting appraisal that is often founded upon different methods, techniques and tools (Jiang et al., 2003; Bao et al., 2006). Moreover, there is a general agreement among atmospheric scientists that a warmer world would be a wetter world, with no increase in the number of days with rain, but with more intense rainfall (Saunders, 1998; Russel et al., 2000). This could generate extreme rainstorms that often can be related to hurricane events (Kerry, 2005; Webster et al., 2005; Trenberth and Shea, 2006). This kind of situation calls for a multidisciplinary and integrated approach with the best available technology. The process of applying numerical models to hurricane hazard mitigation involves prediction, monitoring and safeguarding the environment and population against physical impact. Technologies such as GIS and Remote Sensing have raised great expectations as potential means of coping with natural disasters like hurricane (Yaun et al., 2002; Shipley, 2005).

\footnotetext{
${ }^{1}$ Applied Research Associates, Inc.: National Institute of Building Sciences, and Federal Emergency Management Agency, Research to Develop Advanced Severe Storm Coastal Risk Assessment Methodology Using NASA's WAVEWATCH III and Remote Sensing Technology, unsolicited proposal, NASA, 34 pp., 2003 2006.
}

This research is part of a service agreement between the University of Perugia and the United Nation World Food Programme (WFP) for developing a Multi-Hazard Assessment Tool for hurricane hazard assessment in Central America. The research made use of a number of available remote sensed global datasets in order to satisfy the WFP requirement of free and up to date datasets. Moreover datasets that satisfy these characteristics are often the only data available for developing countries like the ones involved in the WFP activity.

Within this context the selected approach is to determine a sudden onset zoning from a set of available information that are considered to govern the hazard while we examine the influence of each individual events producing the final hazard. Most important parameters to assess the hurricane hazard are topography, bathymetry, storm track into coast proximity, and river network. Complementary data for the final multi-hazard model include daily density rain dataset, and hurricane structure model. The model is then validated on a regional basis using past WFP experience on hurricane frequency study over an area that covers both developed and developing countries in the Central American region.

\section{Description of the study area}

\subsection{The West Indies and Central America}

The West Indies (Anguilla, Antigua and Barbuda, Aruba, Barbados, British Virgin Islands, Bonaire, Cayman Island, Cuba, Dominica, Curacao, Grenada, Guadeloupe, Dominican Republic, Haiti, Jamaica, Martinique, Montserrat, Netherlands Antilles, Puerto Rico, Saint Kitts and Nevis, Saint Lucia, St. Marteen, Saint Vincent and the Grenadines, Trinidad and Tobago, United States Virgin Islands) and Central America (Guatemala, El Salvador, Honduras, Nicaragua, Costa Rica, and Panama) selected as study area are roughly located lat $0^{\circ} \mathrm{S}$ and $30^{\circ} \mathrm{N}$ and long $60^{\circ} \mathrm{E}$ and $110^{\circ} \mathrm{W}$ (Fig. 1).

The study area is a subplate presently attached to the South American plate, with little or no movement between them at this time (Freeland and Dietz, 1971). The related effect is responsible for the lack of deep seismicity there as well as for the inhibiting of volcanism and uplift of the Talamanca Range, Costa Rica (Montero et al., 1992). In this context natural hazards in general is not related to deep geology while the geographic location is favorable to hurricanes hazard assessment especially in the northern and eastern parts of the region. Although largely similar in climatic and biophysical land-use potential (Schumann and Partridge, 1989), the study area displays large economic (World Bank, 1998), environmental and political (Pelupessy, 1991) differences. Especially biophysical, climatic, and socioeconomic gradients (mountain ranges, rainfall, and population density) 
are steep over small distances within the countries, which induces strong variation in land-use over relatively small areas.

\subsection{Climatic background}

Climate in the Caribbean basin can be classified as drywinter tropical (Rudloff, 1981), with significant subregional variations in rainfall annual totals, length of the rainy season, and timing of rainfall maxima. The climatologic (19511980) annual mean rainfall, averaged over all the 188 stations (Giannini et al., 2000), is 1618 millimetres per year. It exceeds 2000 millimetres per year in Costa Rica and along the Caribbean coast of Honduras. Three rainfall regimes can be related to the geography of the Caribbean-Central American region. A May-October rainfall regime is typical of the Central American. A regime characterized by a pronounced midsummer break in rainfall accumulations is typical of the interior of the basin (southern coasts of Jamaica and Hispaniola). A regime characterized by a late-fall peak in rainfall is typical of the Caribbean coast of Honduras, of the northern coasts of Jamaica and Hispaniola, of Puerto Rico and of the Lesser Antilles. In this context rainfall-bearing disturbances, known as African easterly waves (Riehl, 1954; Burpee, 1972), propagate across the Atlantic Ocean into the Caribbean basin from mid June to early October generating hurricanes.

\section{Data source}

\subsection{Hazard assessment}

The multi-hazard model includes a large volume of resident GIS-readable databases, including physiographic data relating to terrain (i.e., land cover), topography, and inventory data pertaining to population density. These datasets include worldwide data on topographic physical characteristic like river network as well as rain density data. The most recent version of the Multi-Hazard Hurricane Model now also takes slope topography into account.

\subsubsection{Topography dataset}

The Shuttle Radar Topography Mission (SRTM) data, characterized by a recent and extensive literature (Grohman et al., 2006; Gorokhovich and Voustianiouk, 2006), is available at the USGS-SRTM seamless Website - http://seamless.usgs. gov - Gesch (2006).

In this analysis we have used the SRTM data version 2. The SRTM in its original format has a resolution of 3arc-seconds, approximately $90 \mathrm{~m} \times 90 \mathrm{~m}$ over the study area. Assemblage and local interpolation of the SRTM was performed importing tiles into ArcInfo 9.x (CESRI) using an Arc-Macro Language procedure (Taramelli and Barbour, 2006). The final grid was projected in the Mercator projection.

\subsubsection{Bathymetry dataset}

The GEBCO One Minute Grid (Jones, 2003) is fully global and includes land elevations from the IGBP GLOBE database (Fig. 1). A medium stage bathymetry datasets exported from GEBCO with $1 \mathrm{~km}$ horizontal resolution were examined in Interactive Visualization Systems software for further cleaning, geomorphic analysis, and exporting grids to ArcMap GIS. Resolution of the bathymetry data was such that landscape features and differences on the order of $1 \mathrm{~km}$ horizontal were clearly discernable. Data were rigorously edited for spurious points and smoothed and gridded to $1 \mathrm{~km}$ interval to minimize data gaps in the final xyz export. The net vertical resolution was multiplied by the single pixel area $(90 \times 90 \mathrm{~m})$ and re-interpolated to arrive at the net value in all areas of the bathymetry.

\subsubsection{Rain dataset}

The Climate Prediction Center Morphing Method $(\mathrm{CMORPH})$ uses motion vectors derived from halfhourly interval geostationary satellite InfraRed imagery to propagate the relatively high quality precipitation estimates derived from passive microwave data. In addition, the shape and intensity of the precipitation features are modified (morphed) during the time between microwave sensor scans by performing a time-weighted linear interpolation (Levizzani and Mugnai, 2004; Joyce and Ferraro, 2005).

The hourly analyses of CMORPH at a grid resolution of $1 \mathrm{~km}$ have been produced using the INGRID programme at the IRI/LDEO Climate data library website (http://ingrid. ldeo.columbia.edu/). The INGRID is an alternative mesh generator for finite element modelling, which is principally used as a fairly complete mesh generator with a wide range of geometric capabilities.

\subsubsection{Winds dataset}

The National Hurricane Center's Tropical Cyclone Reports contain comprehensive information on each tropical cyclone, including synoptic history, meteorological statistics, casualties and damage, and the post-analysis best track (six-hourly positions and intensities). These data are of key-importance in vulnerability assessment. The lesson learnt in past events can really help to strengthen prospective scenarios. Tropical cyclones include depressions, storms and hurricanes (Abraham et al., 2004). In particular the report was used to calculate the standard temperature and pressure $R_{0}$ following the axisymmetric hurricane wind model from Holland (1980). It assumes that for a generic tropical cyclone, surface pressure field follows a modified rectangular hyperbola, as a function of radius in cyclostrophic balance. Even if the axisymmetric is rarely, it is possible to introduce deviation from that geometry in a simple way: dividing for example in quadrants the wind fields. Following the idea proposed in Bao et al. (2006) 


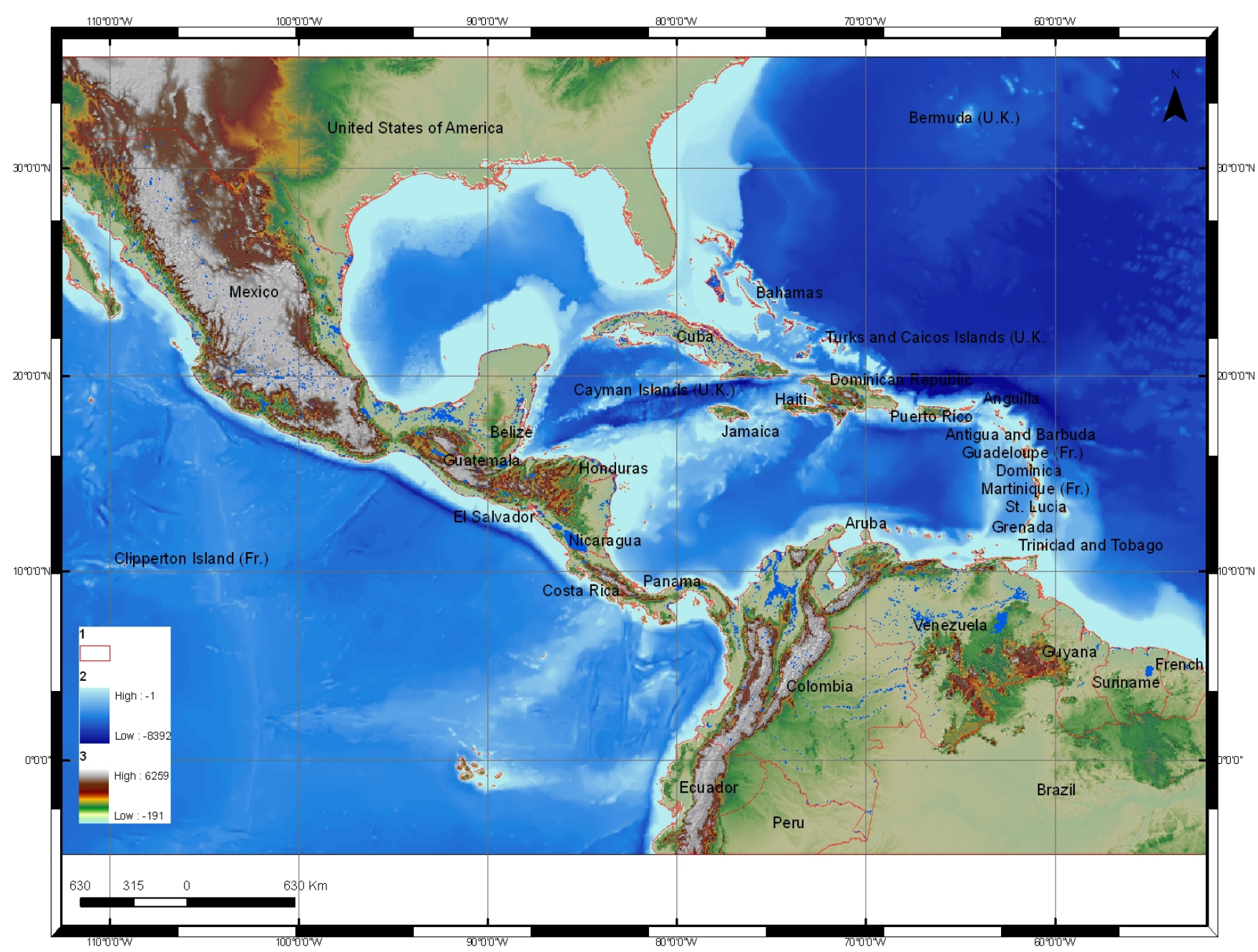

Fig. 1. Location map of the study area: 1) country boundaries; 2) GEBCO bathymetry, 3) SRTM Digital elevation model.

we computed the wind field, for each single quadrants, from the maximum sustained wind observed (Xie et al., 2006) and reported in the NHC website (http://www.nhc.noaa.gov).

\subsection{Elements at risk}

\subsubsection{Land cover dataset}

The Global Land Cover database is being produced by an international partnership (Hansen et al., 2000). The database contains a global product that combines all regional classes in one consistent legend (Mucher and Badts, 2002). To create the final landcover dataset of the study area a reclassification of the different landcover classes was carried out. We decided to use the decision trees approach due to the numerous classes in the landcover dataset (21). Some of them could be clustered within a same class (e.g.: shrub cover with herbaceous cover). Decision trees provide a more rational approach to land cover classification than traditional statistical supervised classification. Decision trees allows the user to specify the exact logical basis of class assignment in the form of a Boolean conditional of arbitrary complexity. So as final classes we have: tree cover, regularly flooded shrub, cultivated and managed areas, cropland, bare areas, water, artificial surfaces and associated areas, irrigated agriculture (Fig. 2).

\subsubsection{Population dataset}

Affected population are assessed on a $2.5^{\prime} \times 2.5^{\prime}$ latitudelongitude grid of global population, the Gridded Population of the World, version 3 (GPWv3). The GPWv3 depicts the distribution of human population across the globe transforming population census data (corresponding to irregularly vector census block and block group boundaries), which most countries collected for subnational administrative units, into a regular raster-grid. Each cell contains an estimate of total population and population density on land, based on the overlap between the irregular boundaries of administrative 


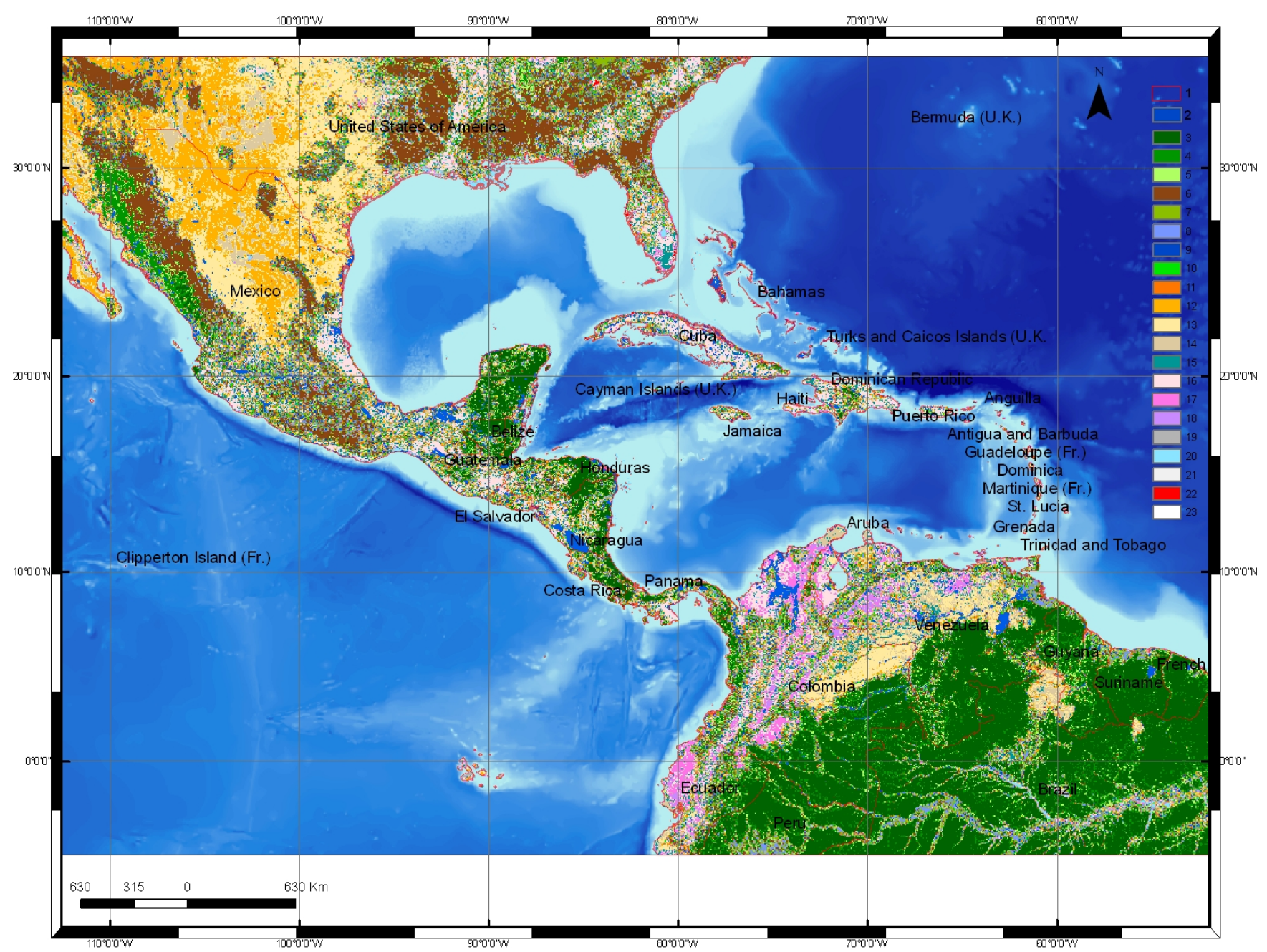

Fig. 2. Land Cover map of the study area: 1) country boundaries, 2) tree cover - evergreen, 3) tree cover - deciduous closed, 4) tree cover deciduous open, 5) tree cover - needle leaved, 6) tree cover mixed leaf type, 7) tree cover regularly flooded fresh water, 8) tree cover regularly flooded saline water, 9) tree cover/other natural vegetation, 10) shrub cover closed-open evergreen, 11) shrub cover closed-open deciduous, 12) herbaceous cover, 13) sparse herbaceous or sparse shrub cover, 14) regularly flooded shrub and herbaceous cover, 15) cultivated and managed areas, 16) cropland, 17) tree cover and other natural vegetation, 18) cropland, shrub and grass cover, 19) bare areas, 20) water, 21) snow and ice, 22) artificial and associated areas, 23) irrigated agriculture.

units and the regular boundaries of the grid. In this analysis (Fig. 3), we used a preliminary version of GPWv3, which contains population estimates for 1990, 1995, and 2000 for approximately 375000 sub-national administrative units (CIESIN et al., 2004).

\section{The Stan event on the Caribbean area}

A tropical wave that moved off the coast of Africa on 17 September 2005 was the likely precursor to Stan (Fig. 4). Cloudiness and showers associated with the system began to increase as the wave neared $50^{\circ} \mathrm{W}$ longitude on 22 September but north-north-easterly shear created an environment that was not favourable for tropical cyclone formation. The wave moved into the eastern Caribbean Sea on 25 September, while shear over the system diminished. By 27 September, deep convection associated with the wave became more consolidated over the central Caribbean Sea. Based on the extent and organization of deep convection as well as surface observations, it is estimated that a tropical depression formed around 12:00 UTC on 1 October centred about $115 \mathrm{nmi}$ southeast of Cozumel. Lower to middle-tropospheric ridging to the north and northeast of the tropical cyclone resulted in a west-north-westward steering current and an uppertropospheric anticyclone became established over the area. The depression strengthened into a tropical storm shortly before its centre made landfall on the east coast of the Yucatan peninsula, just south of Tulum, around 10:00 UTC on 


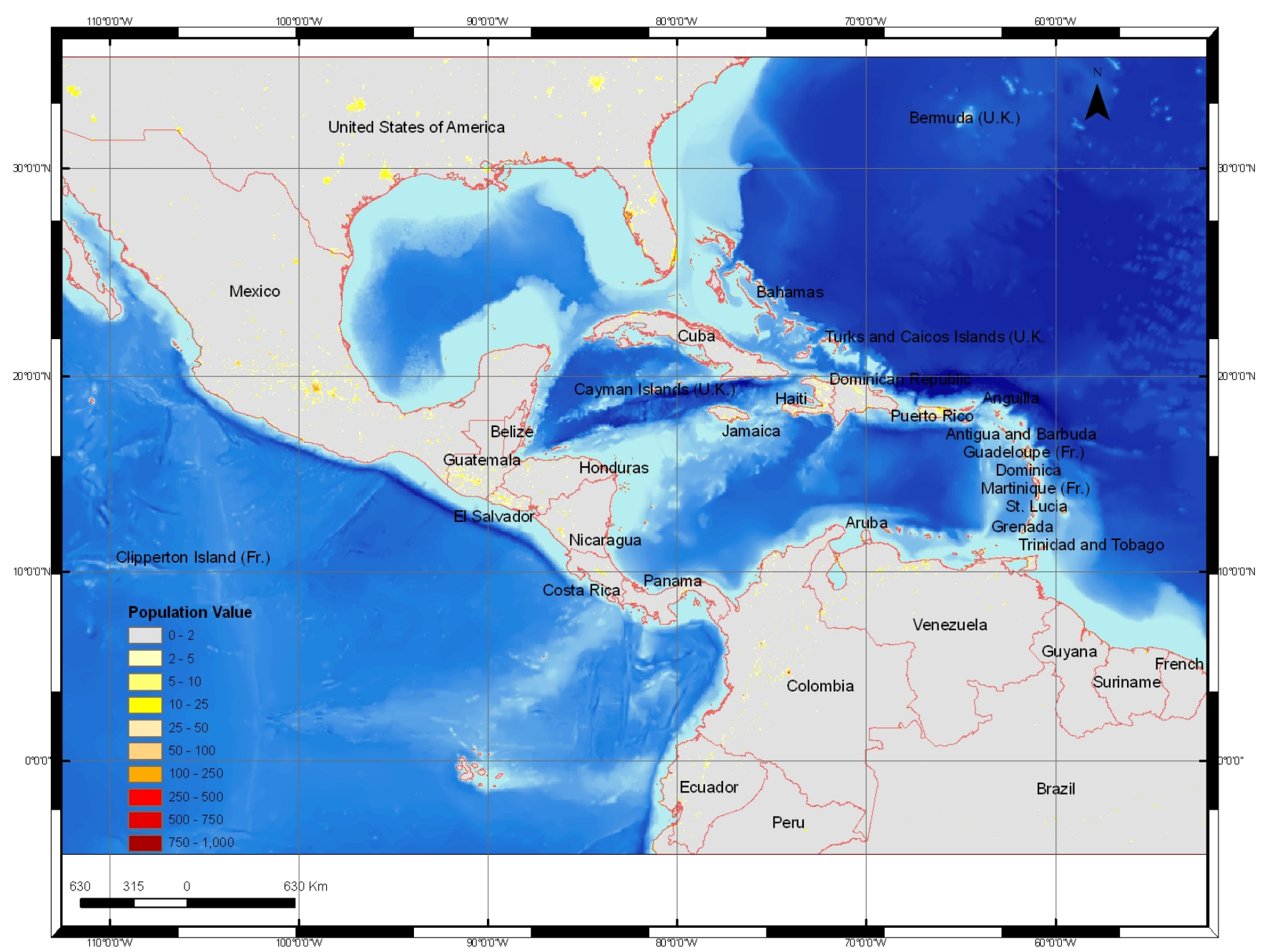

Fig. 3. Estimate of total population and population density of the study area.

2 October. Stan crossed the peninsula in about $18 \mathrm{~h}$ while weakening back to a depression. It quickly regained tropical storm strength, however, after it moved back over water. Deep layer high pressure over the western Gulf of Mexico forced the system to turn toward the west-southwest over the Bay of Campeche. As Stan approached the southern Gulf coast of Mexico, it rapidly intensified into a hurricane around 06:00 UTC on 4 October. The most affected countries were Guatemala, El Salvador, Mexico (its southern and eastern parts), Nicaragua, Honduras and Costa Rica.

\section{Methodology}

Management strategies for hurricane hazards typically require four components: hazard mitigation and preparedness, response to disaster, and subsequent recovery. Specific components of each will partly depend on the nature of the hurricane causing the hazard. In this research the major constraint in using GIS to evaluate hurricane hazard is the complexity of the hazard-generating phenomena. Moreover hazard due to hurricane is the result of interaction of both internal factors such as topography, bathymetry and hydrology, and external factors such as high winds and precipitation (Taramelli and Melelli, 2007). The key issue in forecasting the hurricane hazards is the identification and collection of the relevant predictors whose nature, character and role will vary depending on the type of hurricane and on the geomorphologic and climatic setting of the region affected by the hurricane itself. The steps to build the final structure of the hurricane multihazard GIS model presented in this research are (Fig. 5):

- georeferentiation of the location sites and their spatial attributes (topography, bathymetry and precipitation);

- modelization of the hurricane hazard related to three different events such as storm surge, high winds and floods;

- examination of the spatial distribution of the hurricane hazard; 


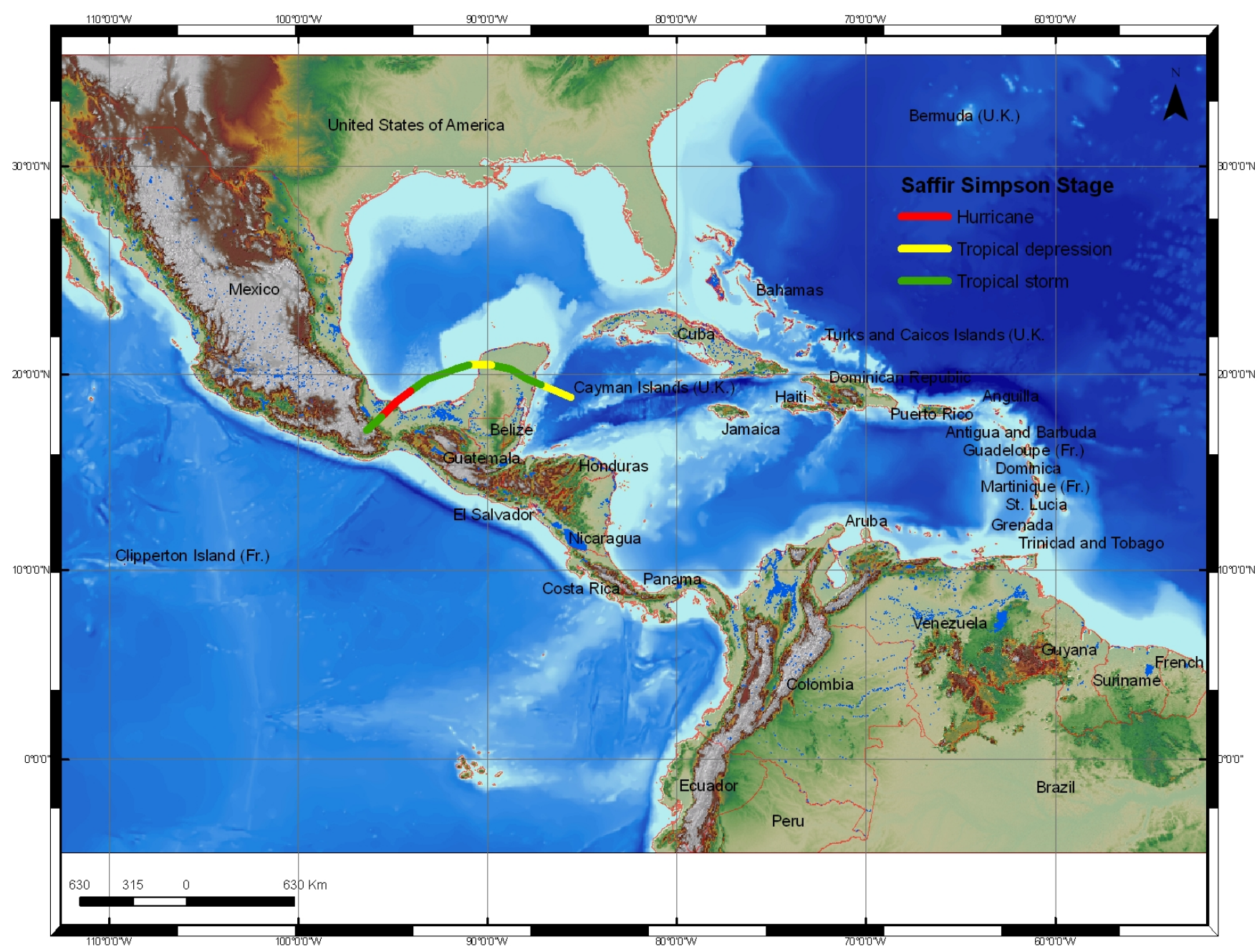

Fig. 4. Hurricane track of the Stan Event.

- analysis of the elements to be affected by the events (overlay analysis with the land cover and population dataset).

\section{Storm surge}

Storm surges are oscillations of the water level in a water body having period range from a few minutes to a few days, associated with a low pressure weather system (Blain, 1997; Gonnert et al., 2001). Although storm surges belong to the same class known as long gravity waves, as do tides and tsunamis, there are at least two important differences. First, whereas tides and tsunamis occur on the oceanic scale, storm surges are simply a coastal phenomena. Second, storm surge is defined as an abnormal, sudden rise of sea level associated with a storm event. Storm surges result from the combination of low barometric pressure, strong onshore winds and higher than normal tides (Goring, 1999). Most commonly, storm surge elevation of sea level occurs in response to a decrease in atmospheric pressure, to an increase in wind stress on the surface of the ocean and to the slope of the bathymetry and of the coast. Due to this fact, storm surge is generally constant over a large area (Munro, 1999).

The model implemented in this project calculates the proportional height of the bathymetry near the coast line and consequently the hazard degree value onshore related to the slope angle of the topography (Fig. 6).

The storm surge was calculated using SRTM DEM and GEBCO Dataset in ArcGIS 9.x software (ESRIC). The analysis was cast in different steps:

- the coastline was modelled as a polyline for the study area using the NOAA/NOS Medium Resolution Coastline designed for 1:70000 (available at: http://www. ngdc.noaa.gov/mgg/shorelines/shorelines.html);

- based on literature data (Blain et al., 1994, 1998; Zenger et al., 2002) a $5 \mathrm{~km}$ width buffer was calculated around 


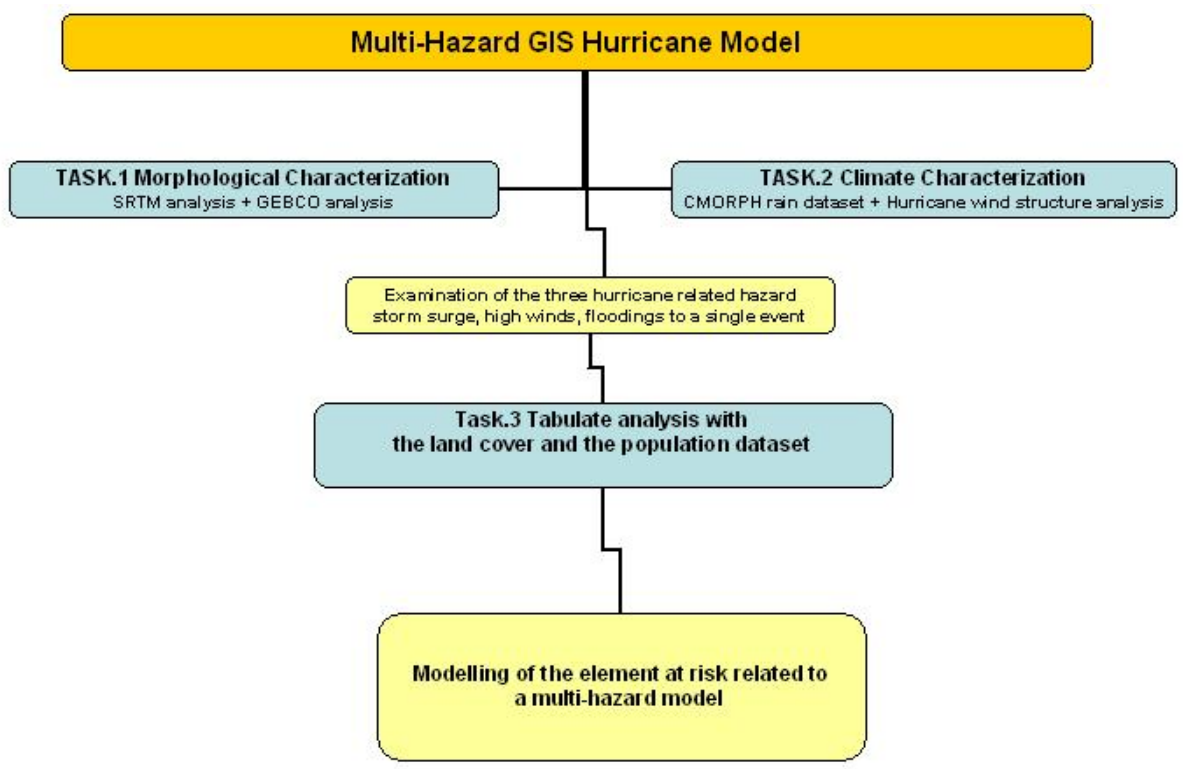

Fig. 5. Flow chart of the GIS hurricane early warning model.

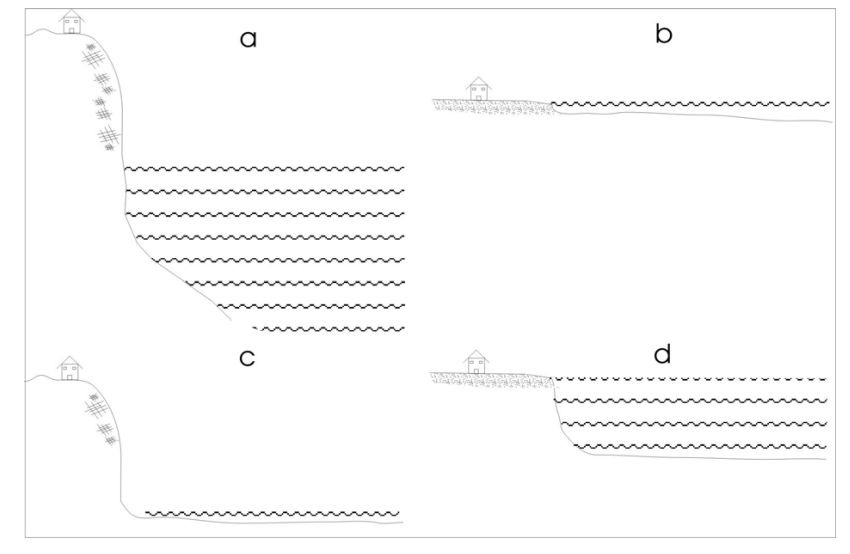

Fig. 6. (a) low hazard degree with high slope angle and deep water, (b) high hazard degree with low slope angle and shallow water, (c)-(d) medium hazard degree with medium slope angle/shallowmedium water deep.

the coastline for the far reachable distance value onshore;

- for both onshore and offshore potentially affected area slope grids were calculated respectively from SRTM, GEBCO datasets.

- Both slope grids were reclassified in three increasing storm surge hazard classes (from value 1 minimum hazard to value 3 , maximum hazard).

- Finally, we produced a final storm surge hazard assessment identifying every grid node, within the $5 \mathrm{~km}$ coastline buffer area, having the three different hazard val- ues. The resulting grid (see Fig. 7) shows values that vary from 1 to 3 , indicating respectively the greatest, the medium and the lowest likelihood of hazard signatures.

For Stan event (Fig. 7a) the potentially affected area is around $36 \mathrm{~km}^{2}$ whereas the potentially affected population is near 22524 persons. Figure $7 \mathrm{~b}$ shows the distribution of the areas and the population in the three storm surge hazard classes.

\subsection{Floods}

A flood related to an hurricane event occurs when a stream overflows after prolonged intense rainfall over several days. The intensity of a flood varies widely from one site to another because of local conditions. A simple representation of flood affected areas in a way that is easily grasped by the early warning managers, but still accurate and scientifically sound, is an important product of a flood study. With this concern in mind, there is much to gain in coupling the traditional and cumbersome hydrologic modelling with advanced and sophisticated computer tools within GIS. Hydrologic modelling deals frequently and extensively with spatial data. Input, parameters and output are space-time defined. In this context different studies (Tucker et al., 2000; Tarboton and Ames, 2001; Hancock and Evans, 2004) investigate the flood modelling through the use of Digital Elevation Models (DEMs). In this research the most important variables relevant to flood hazard assessment are: meteorological data (rainfall depths and intensities, magnitude and frequency of rain peak) and topographic data of the catchment basins struck by the hurricane. Due to spatial data integration issues within GIS such as geographical scales of the study area, the geologic factors as permeability and soil 


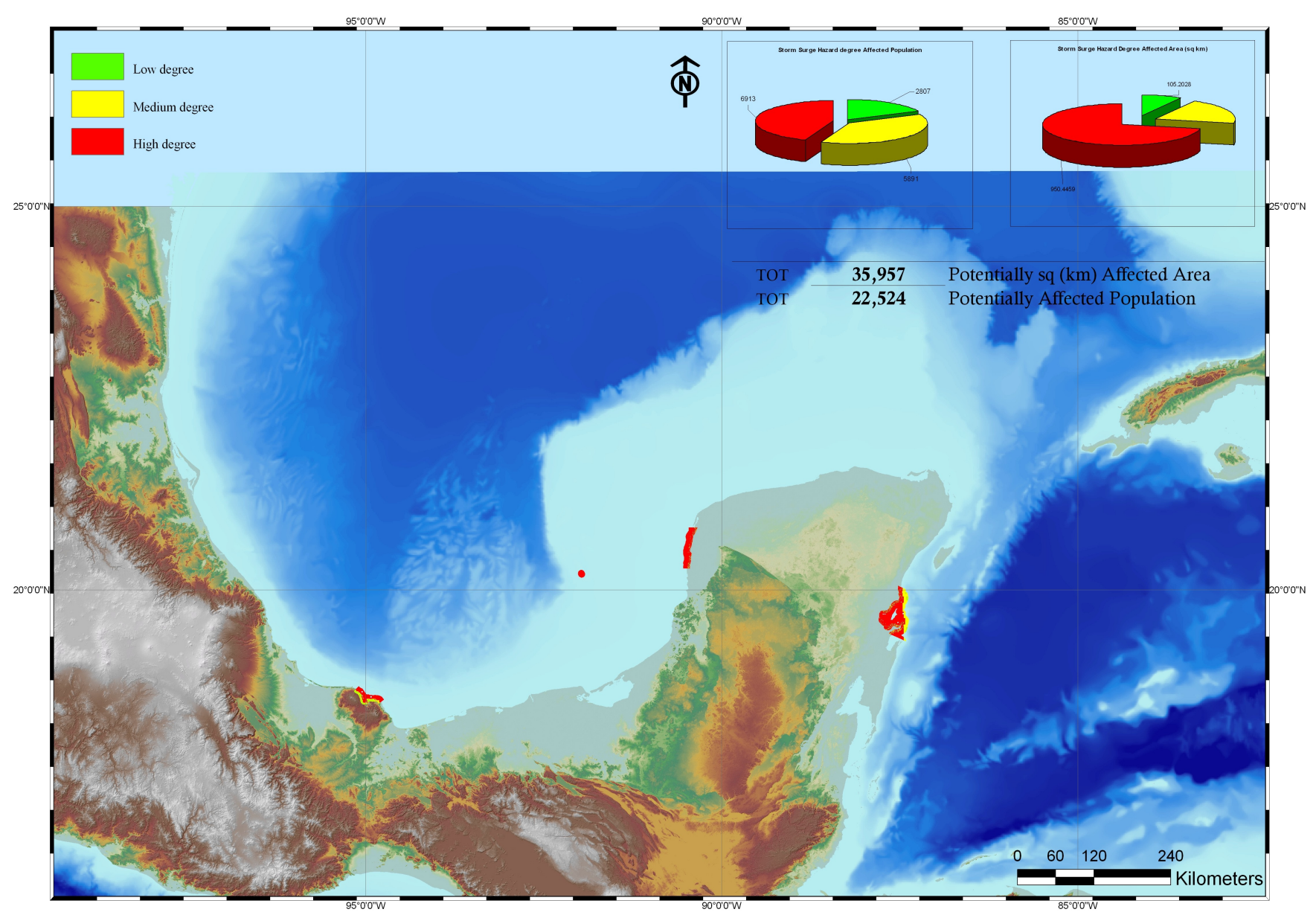

Fig. 7. Storm surge hazard assessment related to the Stan hurricane event. (a) storm surge affected population of the study area, (b) storm surge affected area.

type are not taken into account. The final flood hazard analysis was cast in different steps using ArcGIS 9.x software (ESRIC):

- The delineation of flow direction grid is carried out exploiting the eight-direction pour point model (Puecker and Douglas, 1975).

- The method of Jenson and Domingue (1988) is used to determine the flow accumulation grid.

- The stream network in a grid structure is then derived.

- The stream network is classified according to Strahler method (Strahler, 1980) assigning a numeric order to links in a stream network based upon their number of tributaries. For the study area according to previous studies (Correia et al., 1998; Colby et al., 2000; Taramelli and Melelli, 2007) the forth order is the maximum value assigned.

- The river network grid is converted in a vector layer (polyline) and then a buffering is made in order to link the stream order to a potential affected flooded area considering a linear proportional relation between the two variables. Based on literatures (Penning-Rowsell and Fordham, 1994; Penning-Rowsell, 1996; Correia et al., 1999) a buffering width equal to $200 \mathrm{~m}$ is measured for the first order, $1000 \mathrm{~m}$ for the second, $2000 \mathrm{~m}$ for the third and $4000 \mathrm{~m}$ for the fourth one. Then the buffer layers area is converted in a grid format with the river order value that is assigned to each pixel.

- The wetness index is calculated using the Terrain Analysis using Digital Elevation Models (TauDEM) plug-in (Tarboton, 1998; Tarboton and Ames, 2001) in order to consider into the hydrologic model the topographic parameter of the flooding areas. This calculation estimates the ratio Slope/Specific Catchment Area, where a specific catchment area is the ratio between a contributing area concerning a specific unit contour length along the slope. This is algebraically related to the more common $\ln (\mathrm{a} / \mathrm{tan}$ beta) wetness index, with the contributing area at the denominator to avoid errors dividing by 0 when 


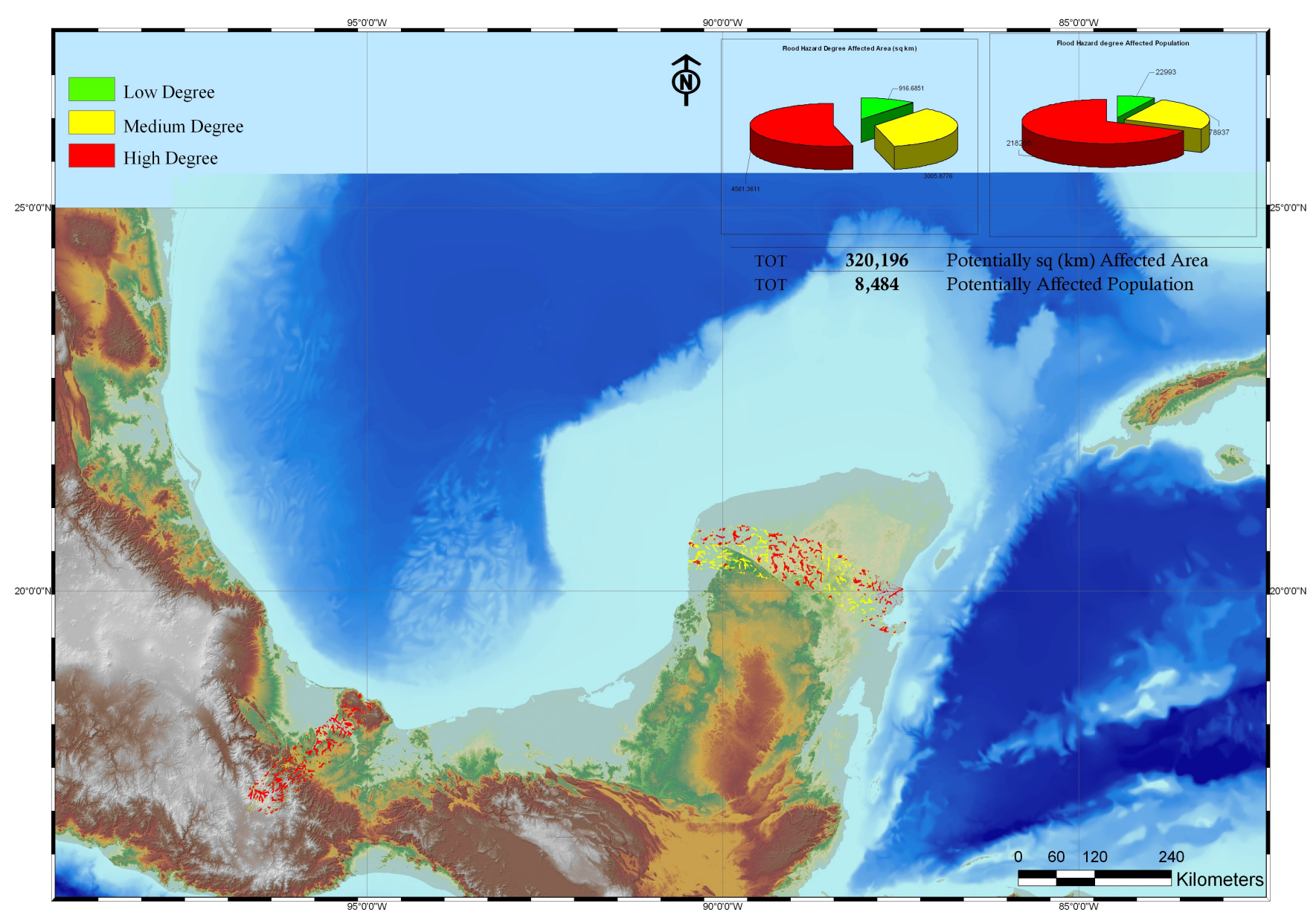

Fig. 8. Flooding hazard assessment related to the Stan hurricane event. The assessment of the rain-rate is within the watershed area using cumulate values. (a) flooding affected population of the study area, (b) flooding affected area.

the slope value is $0^{\circ}$ (Costa-Cabral and Burges, 1994; Tarboton, 1998).

- The wetness index grid is reclassified in three increasing hazard degree classes. This grid relies on topographic variables only and it is still independent from specific rain values.

- A CMORPH rain dataset for the specific Stan hurricane event (between 1 and 5 October 2005) is calculated in the INGRID mesh generator. It is interesting to notice that high rain values are present not only near by the hurricane track but also far away from the eye of the event due to the topography of the test area. The total rain values grid is then overlaid to the wetness index one achieving the final flooding hazard grid. Each area is zoned in terms of degree of hazard and each zone is numerically scored. The affected areas are categorized in terms of no flooding, medium flooding and high flooding and allocated the numeric values $0,1,2$ and 3 respectively. We produced a final flooding hazard assessment identifying every grid node within the zones hav- ing only three different hazard values that fall within the sum of evidence criteria using the reclassify operator in a GIS environment. The resulting grid shows values that vary from 1 to 3 , indicating respectively the lowest, the medium and the greatest likelihood of hazard signatures (Fig. 8).

For Stan event (Fig. 8a) the potentially affected area is around $321 \mathrm{~km}^{2}$ whereas the potentially affected population is near 8500 persons. Figure $8 \mathrm{~b}$ shows the distribution of the areas and the population in the three flooding hazard classes.

\subsection{High winds}

Another key variable in the hurricane hazard is the estimate of the area struck by the high winds. In the absence of detailed instrument observations we assumed that wind velocity increases linearly from the centre to the outer side (Holland, 1980; Holweg, 2000) and thereafter decreases exponentially moving outwards. Moreover, the horizontal wind field is asymmetrical and, in northern hemisphere, the strongest 
winds are found in the right-hand quadrants of the storm (relative to the direction of movement) due to the Coriolis force.

Based on the aforesaid basic model, in this study we used the NOAA preliminary hurricane report (Xie et al., 2006; Pasch and Roberts, 2006) in order to gain all the comprehensive information on each hurricane, including synoptic history, meteorological statistics and the post-analysis best track (six-hourly positions and intensities). The track and the intensity evolution (from NHC) of the hurricane Stan, shown in Fig. 4, are the first input of the model as lat-long point features. Then the term intensity evolution of the hurricane event referred to the temporal variation of the $R_{0}$ while changes in near-eye wind mean velocity, near-eye diameter, atmospheric pressure are documented to check whether the models storm evolve (Xie et al., 2006). In order to estimate the potentially affected areas by high winds we worked trough a processing sequence:

- the first thing was to import as event theme the lat-long txt file from the NOAA preliminary report,

- we assessed the cyclone's mean sustained surface wind, based on the radius maximum winds speed and on the pressure within the same radius. The wind at each level of the hurricane has been normalized by the wind speed of the different quadrant based on the asymmetric modelling of the hurricane itself and the $V(R)$ velocity was calculated based on the Holland model for each quadrants and computing all the model parameters from the hurricane report in the NHC web page (Fig. 9),

- we evaluated the ratio of the $R_{0}$ East and $R_{0}$ West related to the stage of the Saffir-Simpson scale of the Hurricane (Blong, 2003). The ratio is 0.8 for the $R_{0}$ West and 1.2 for the $R_{0}$ East,

- the two different $R_{0}$ value were calculated and then joined with the $\mathrm{XY}$ event theme to generate a polyline vector file,

- a rounded buffer file was created using the two different $R_{0}$ values leading to polygon vector file within the value of $R_{0}$ intensities that represent intensity evolution of the hurricane event referred to the temporal variation of the $R_{0}$,

- we finally converted the polygon vector file to an integer grid file representing the different hazard values. Values for the resulting dataset, which we term degree values, vary continuously from 1 to 3 , with 1 representing terrain with low hazard degree and 3 indicating that all of the terrain exhibits high hazard degree (Fig. 10).

As a preliminary result, it can be noticed that high values of the signature are represented with red, medium values with yellow and low values with light green. As can be seen, in addition to the relatively homogeneous values near the coastal

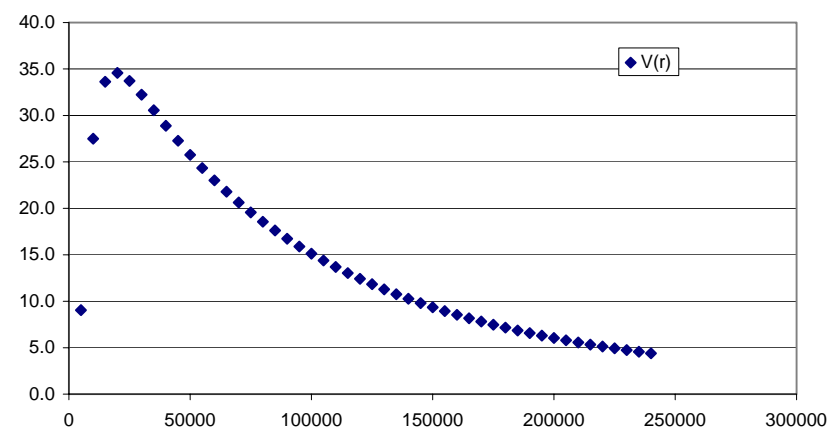

Fig. 9. Plot of the $V r$ values. $\mathrm{X}$ values are the radius of the hurricane track (m); Y values are the $V r$ values $(\mathrm{m} / \mathrm{s})$.

area, there is a wide variety of different signal showing out throughout the ridge region and a widespread boundary region areas of strongly high value composition.

For Stan event (Fig. 10a) the potentially affected area is around $36000 \mathrm{~km}^{2}$ whereas the potentially affected population is near 1407 people. Figure $10 \mathrm{~b}$ shows the distribution of the areas and the population in the three high winds hazard classes.

\section{Discussion}

The main objective of our GIS approach was the analysis of the morphogenetic and atmospheric parameters influencing the hurricane effects, for the purpose of identifying the key factors for a methodology concerning a multi-hazard model. In order to obtain a final hazard assessment we have been working on the analysis models to produce first:

- Areas potentially affected by storm surge,

- Areas potentially affected by high speed winds,

- Areas potentially affected by floods.

Each zone was numerically scored and each theme was zoned in terms of degree of hazard. The themes were categorized in terms of no hazard, low hazard, medium hazard, high hazard and allocated the numeric values 0,1,2 and 3 respectively. This process was done with each hazard theme. Finally, based on the single hazard results, we produced a final multi-hazard assessment identifying every grid node within the area having the three different hazard values that fall within the model criteria using the boolean (and) overlay in a GIS environment. This was done in order to consider always each single high hazard degree even if the other two were not happening in the same area. The resulting grid, shows values that vary from 1 to 3 , indicating the greatest, the medium and the lowest likelihood of hazard signatures, respectively by 3, 2 and 1 (see Fig. 12). So that the final multi-hazard was coded into three classes: 


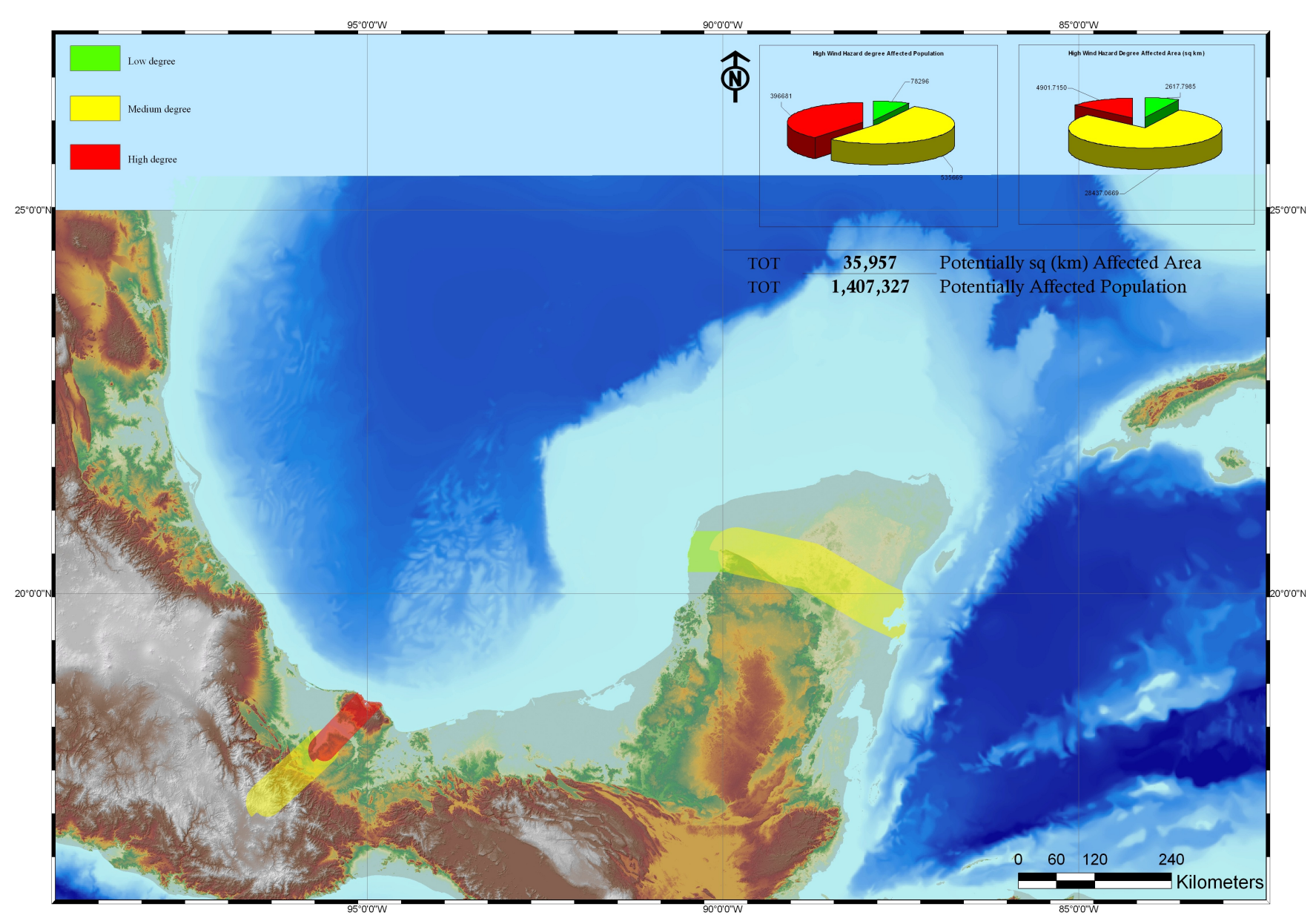

Fig. 10. High winds hazard assessment related to the Stan event. (a) High winds affected population of the study area, (b) high winds affected area.

- high (all the three hazards have high value),

- medium (two of the three hazards have high value),

- low (at least one of the three hazards have high value).

After that, the elements at risk were evaluated for each hazard zone. The risk assessment requires that critical facilities are identified and data on past physical effects, in terms of structural and functional damage be collected. This allows to enquiry the same datasets for each hurricane events, knowing the track and the physical characteristics of the event, obtaining, for each example, the risk evaluation. This data are to be entered into a database and integrated into a GIS. In this research, instead, to assess the overall elements at risk, the hazard results were overlaid only with population and landcover datasets. The approach was then validated on a regional basis using the Stan event report on elements affected by damaging events (OCHA, 2005) over an area that covers both developed and developing countries in the Caribbean Region. The reports allows to know the effects of Stan event in the study area and to compare the numbers obtained from the model (in terms of affected area and population) to the real effects summarized in the regional reports. So that the key layers in the GIS model are to be the hazard maps of high wind, storm surge and floods with the elements at risk spatial layers of features to be included such as agricultural and managed areas and number of population at a pixel scale. The final elements at risk assessment as set out in this research consist of the following:

- identification of the hazard,

- creation of the specific elements at risk zone maps,

- calculation of a total score of population and total area affected for each single hazard and for the final hazard.

The design of the multi-hazard GIS model seeks to automate the assessment process because it facilitates the conduct of spatial and tabular analysis to calculate the area and population estimation scores. In each hazard area, the hazard boundaries were used to perform a "tabulate" analysis in each available "elements at risk" datasets. So that the "tabulate" 


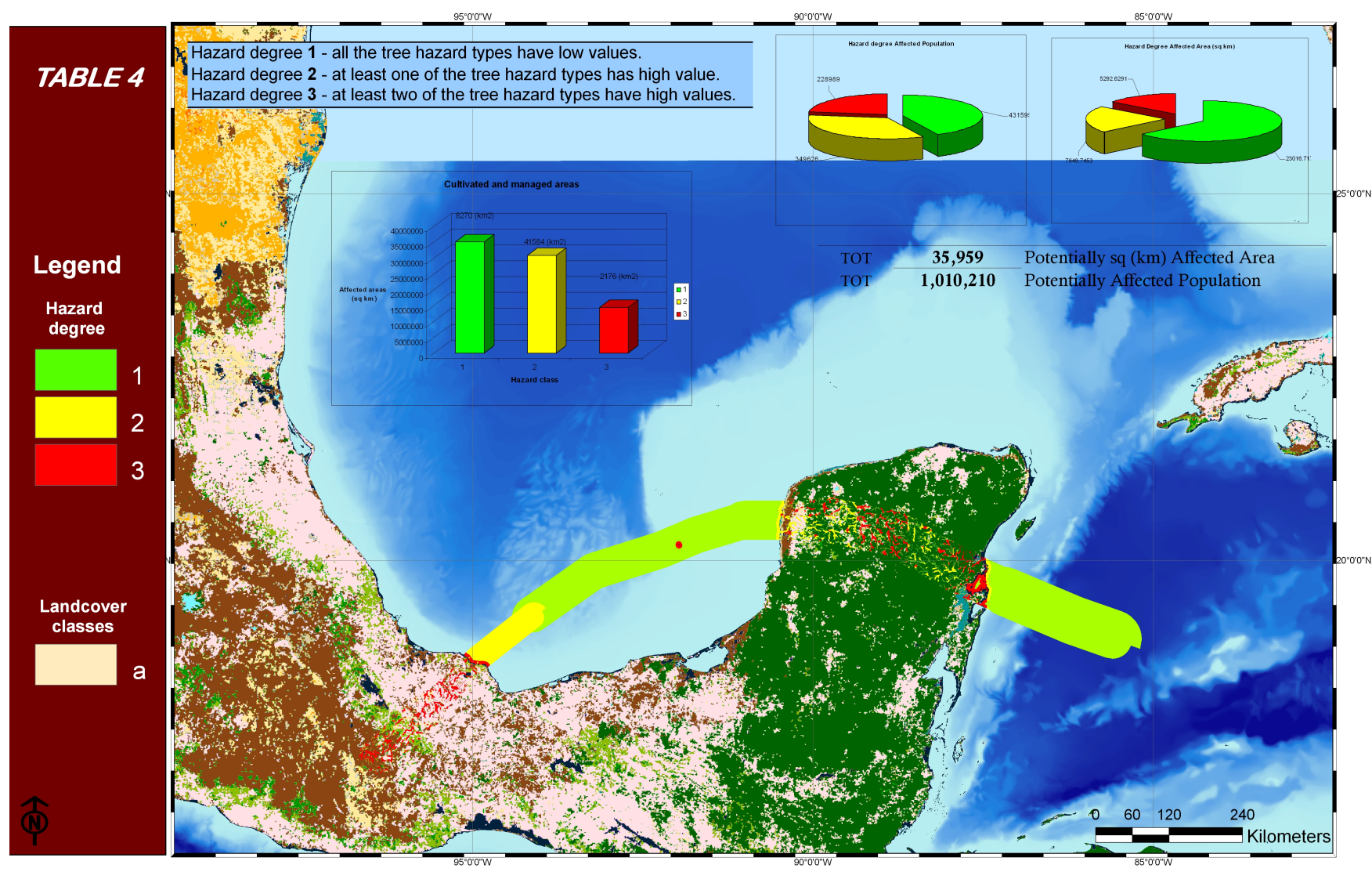

Fig. 11. Final overlay between the sum of the three hazards and the gridded population dataset and the land-cover reclassified dataset.

function, was used to compute the estimation score using the buffer class of the hurricane track as polygon masks. On the basis of the different hazard entities determined, three tables were created: high winds, storm surge and floods estimated population. Then once a set of grids has been created on the basis of the three tables, it was possible to calculate link-bylink statistics in with the ZONALSTATS command. The output is an attribute table, which has an entry for every zone. In this research the zone is a grid of the three hazard values and only includes the equation for a population table, the managed and cultivated areas tables, and the human settlements table. A first analysis shows the results of the three different sums of the hazards (Fig. 11).

The final score of the population and affected area is shown in the tables.

It is important to note that the final affected population and total affected area related to the hurricane Stan final score estimation appeared to be embedded within the western portion of a broader-scale low-level cyclonic circulation. This larger system produced extensive very heavy rains over portions of extreme eastern Mexico and Central America that resulted in disastrous floods. Estimates of the total number of lives lost in Mexico and Central America are mostly in the range of 1000 to 2000, some even higher (OCHA, 2005a, b). Guatemala was hit particularly hard and over 1000 persons may have perished only in that country (UNEP-OCHA, 2005). As can be seen, in addition to the relatively homogeneous values of hazard signature near the coastal area, there is a wide variety of different signal showing out throughout the ridge region and a widespread boundary region areas of strongly high value composition far away from the hurricane track. This widespread signature confirms the high correlation between the affected population score and the flooding environmental variables, while shows an overestimation score between the affected population and the storm surge hazard, probably due to some weak in the storm surge modelling such as the non consideration of the impact angle effect.

In order to finally calculate the estimate of the affected population we look at the population living in the potentially affected areas, comparing the data with the land cover use (in this case the cultivated-managed area and artificial surface). To this end, we get a final rough estimate of the affected population based on the information available. The number of the potentially population is estimated out of a certain percentage, based on the hazard evaluation, out of the population living in the affected area (Fig. 11a). 
The multi-hazard GIS model developed for elements at risk assessment produces through a mix of tabular and spatial manipulations for specific population estimation scores for critical land cover and specifically for topographic parameters. It can be noticed that topography highlights several high score values thought-out areas well far from the point where the hurricane makes the landfill. This is a consistent result with a high correlation with the estimate score of the affected population estimate by field reports (Fig. 11b). Although these scores are a measure of relative elements at risk they can be utilized to identify areas at highest susceptibility to hurricane events.

\section{Conclusion}

As computing and other technologies evolve, there will be an increasing demand for innovative theories and practical applications of in hurricane multi-hazards model. An integrated approach to hurricane hazards assessment is enhanced when examined in a GIS environment. The challenges in data integration include creatively dealing with spatial data-related issues, exploring spatial analysis methods for effectively modelling hazards, vulnerability, and risk assessment, and developing methodologies and tools for supporting rational decision-making applications. High-quality GIS databases support subsequent spatial assessment and rational decisionmaking tasks in a spatial and temporal context, which can help hazard managers and the public understand how complex hazards and their consequences will affect vulnerable communities.

This paper has promoted a structured and integrated approach to hurricane hazards assessment primarily from a quantitative perspective. The approach can have further positive implications. First, the integration of environmental and socio-economic data and subsequent spatial analyses in a GIS environment will provide insights into the interactions between physical hazards and vulnerabilities. Second, the integrated approach is conducive to a multiple natural hazards assessment and multiple hazards mapping related to hurricanes. Third, as the integrated approach to hurricane hazard assessment is compatible with other types of GIS applications and hazard assessment can be systematically conducted along with, or embedded within, regional development planning of different economic sectors. The issues examined in this paper are by no means exhaustive and some concerns, such as errors and uncertainties associated with data and modelling, are generic to GIS applications and should be always considered for any reliable hurricane hazard assessment.

Acknowledgements. The authors are grateful to Francesca Guarnieri for the help in developing the wind model calculation and the two unknown referee for their useful review and for suggestions and interest through it all. We would also like to acknowledge the support of Giorgio Sartori within the WFP Service agreement.
Edited by: K. Chang

Reviewed by: S. Sterlacchini and two other anonymous referees

\section{References}

Abraham, J., Strapp, J. W., Fogarty, C., and Wolde, M.: Extratropical transition of hurricane Michael. American Meteorological Society, BAMS - Sept. 2004, 1323-1339, 2004.

Alexander, D.: Globalization of disaster: trends, problems and dilemmas, J. Int. Aff., 59(2), 1-22, 2006.

Alcantara-Ayala, I.: Geomorphology, natural hazards, vulnerability and prevention of natural disasters in developing countries, Geomorphology, 47(2-4), 107-124, 2002.

Bao, S., Xie, L., and Pietrafesa, L. J: An asymmetric hurricane wind model for storm surge and wave forecasting, AMS Annual Meeting, Atlanta, 2006.

Bausch, D.: HAZUS: FEMA's GIS-Based risk assessment tool, Proceedings of the Geospatial Information \& Technology Association's 7th Annual Conference and Exhibition: A Geospatial Odyssey, http://gisdevelopment.net/proceedings/gita/2003/ disman/dism09.shtml, last access: 8 August 2008, 2003.

Bell, H. M. and Tobin, G. A.: Efficient and effective? The 100 year flood in the communication and perception of flood risk, Environmental Hazards, 7(4), 302-311, 2007.

Blain, C. A.: Modelling methodologies for the prediction of hurricane storm surge, Recent Advances In Marine Science and Technology, 96, 177-189, 1997.

Blain, C. A., Westerink, J. J., and Luettich, R. A.: The influence of domain size on the response characteristics of a hurricane storm surge model, J. Geophys. Res., 99(18), 467-479, 1994.

Blain, C. A., Westerink, J. J., and Luettich, R. A.: Grid convergence studies for the prediction of hurricane storm surge, Int. J. Numer. Meth. Fl., 26, 369-401, 1998.

Bocco, G., Mendoza, M., and Velazquez, A.: Remote sensing and GIS-based regional geomorphological mapping - a tool for land use planning in developing countries, Geomorphology, 39(3-4), 211-219, 2001.

Boyd, K., Hervey, R., and Stradtner, J.: Assessing the vulnerability of the Mississippi Gulf Coast to coastal storms using an on-line GIS-based coastal risk atlas, Proceedings of the OCEANS 2002 MTS/IEEE Conference and Exhibition, 29-31 October 2002, Biloxi, MS, 1234-1240; also available at: http://www.ncddc. noaa.gov/cra/Papers/vuln_paper, last access: 8 August 2008, 2002.

Burpee, R. W.: The origin and structure of easterly waves in the lower troposphere of North Africa, J. Atmos. Sci., 29, 77-90, 1972.

Burrough, P. A.: GIS and geostatistics: essential partners for spatial analysis, Environ. Ecol. Stat., 8, 361-377, 2001.

Carson, T. N. and Arthur, S. T.: The impact of land use-land cover changes due to urbanization on surface microclimate and hydrology: a satellite perspective, Global Planet. Change, 25, 49-65, 2000.

Center for International Earth Science Information Network (CIESIN), Columbia University and Centro Internacional de Agricultura Tropical (CIAT): Gridded Population of the World (GPW), Version 3, Palisades, NY: Columbia University, available at: http://beta.sedac.ciesin.columbia.edu/gpw, last access: 8 August 2008, 2004. 
Colby, J., Mulcahy, K., and Wang, Y.: Modelling Flooding Extent from Hurricane Floyd in the Coastal Plains of North Carolina, Environmental Hazards, 2, 157-168, 2000.

Correia, F. N., Rego, F. C., Saraiva, M. G., and Ramos, I.: Coupling GIS with hydrologic and hydraulic flood modelling, Water Resour. Manag., 12, 229-249, 1998.

Correia, F. N., Saraiva, M. G., and Ramos, I.: GIS-Based Flood Analysis and Floodplain Management, Water Resour. Manag., 13(1), 23-37, 1999.

Costa-Cabral, M. and Burges, S. J.: Digital Elevation Model Networks (DEMON): A Model of Flow Over Hillslopes for Computation of Contributing and Dispersal Areas, Water Resour. Res., 30(6), 1681-1692, 1994.

Emmons, H. W., Chang, C. T., and Watson, B. C.: Taylor instability of finite surface waves, Journal of Fluid Mechanics Digital Archive, 7, 177-193, doi:10.1017/S0022112060001420, 2006.

Freeland, G. L. and Dietz, R. S.: Plate Tectonic Evolution of Caribbean-Gulf of Mexico Region, Nature, 232, 20-23, 1971.

Giannini, A., Kushnir, Y., and Cane, M. A.: Interannual Variability of Caribbean Rainfall, ENSO and the Atlantic Ocean, J. Climate, 13, 297-311, 2000.

Gonnert, G., Dube, S. K., Murty, T. S., and Siefert, W.: Global Storm Surges: Theory. Observations and Applications, edited by: German Coastal Engineering Research Council, 63, 623 pp., 2001.

Goring, D.: Getting a handle on extreme sea-levels, Aniwaniwa, 11, 3-12, 1999.

Gorokhovich, Y. and Voustianiouk, A.: Accuracy assessment of the processed SRTM-based elevation data by CGIAR using field data from USA and Thailand and its relation to the terrain characteristics, Remote Sens. Environ., 104(4), 409-415, 2006.

Grohman, G., Kroenung, G., and Strebeck, J.: Filling SRTM voids: the Delta Surface Fill Method, Photogramm. Eng. Remote Sens., March, 3, 213-216, 2006.

Guzman-Tapia, Y., Ramirez-Sierra, M. J., Escobedo-Ortegon, J., and Dumonteil, E.: Effect of Hurricane Isidore on Triatoma dimiata distribution and chagas disease transmission risk in the Yucatan peninsula of Mexico, Am. J. Trop. Med. Hyg., 73(6), 1019-1025, 2005.

Hayden, M. H., Drobot, S., Radil, S., Benight, C., Gruntfest, E. C., and Barnes, L. R.: Information sources for flash flood warnings in Denver, CO and Austin, TX, Environmental Hazards, 7(3), 211-219, 2007.

Hancock, G. R. and Evans, K. G.: Channel head location and characteristics using digital elevation model, Earth Surf. Process. Landforms, 31, 809-824, 2004.

Hansen, M., Defries, R., Townshend, J. R. G., and Sohlberg, R.: Global land cover classification at $1 \mathrm{~km}$ resolution using a decision tree classifier. Int. J. Remote Sens., 21, 1331-1365, 2000.

Holland, G. J.: An analytic model of the wind and pressure profiles in hurricanes, Mon. Weather Rev., 108, 1212-1218, 1980.

Holweg, E. J.: Mariner's guide for hurricane awareness in the North Atlantic Basin, National Weather Service, United States, 2000.

Howard, R., Dodge, P., Doggett, A., Finney, J., Gurley, K., Levitan, M., Reinhold, T., Schroeder, J., and Stone, G.: The Landfall of Hurricane Lili in Louisiana: A Summary of Cooperative Data Collection Efforts, International Conference on Wind Engineering, Lubbock, Texas, 2003.

Jiang, H., Halverson, J. B., and Simpson, J.: Difference of rainfall distribution for tropical cyclones over land and ocean and rainfall potential derived from satellite observations and its implication on hurricane landfall flooding prediction, J. Hydrometeor, 12(1), 29-43, 2003.

Jenson, S. K. and Domingue, J. O.: Extracting topographic structure from digital elevation data for geographic information system analysis, Photogramm. Eng. Remote Sens., 54(11), 1593 1600, 1988.

Jones, M. T.: User guide to the Centenary Edition of the GEBCO Digital Atlas and its data sets, available at: http://www.ngdc. noaa.gov/mgg/gebco/, last access: 8 August 2008, 2003.

Joyce, R. J. and Ferraro, R.: Improvements of CMORPH Resulting from Limb Adjustments and Normalization of AMSU-B Rainfall, 14th Conference on Satellite Meteorology and Oceanography, 28 January-2 February 2006, Atlanta, USA, available at: http://ams.confex.com/ams/pdfpapers/104615.pdf, last access: 11 August 2008, 2006.

Kerry, E.: Increasing destructiveness of Tropical Cyclones over the past 30 Years, Nature, 436, 686-688, 2005.

Klein, R. J. T., Nicholls, R. J., and Thomalla, F.: Resilience to natural hazards: how useful is this concept?, Environmental Hazard, 5(1-2), 35-45, 2004.

Kok, K. and Winograd, M.: Modelling land-use change for Central America, with spatial reference to the impact of hurricane Mitch, Ecol. Model., 149, 53-69, 2002.

Levizzani, V. and Mugnai, A.: Rainfall measurements from space: Where are we?, Proc. 14th Int. Conf. on Clouds and Precipitation, Bologna, Italy, 18-23 July, 2004.

van Lynden, G. W. J. and Mantel, S.: The role of GIS and remote sensing in land degradation assessment and conservation mapping: some user experiences and expectations, Int. J. Appl. Earth Obs., 3(1), 61-68, 2001.

Melelli, L. and Taramelli, A.: An example of debris-flows hazard modelling using GIS, Nat. Hazards Earth Syst. Sci., 4, 347-358, 2004, http://www.nat-hazards-earth-syst-sci.net/4/347/2004/.

McInnes, R. G.: Responding to the risks from climate change in coastal zones, a good practice guide, Ventnor: Isle of Council, 2006.

McInnes, R. G, Tomalin, D., and Jakeways, J.: Coastal change, climate and instability, EU Environment LIFE project, Ventnor: Isle of Council, 2000.

Montero, W., Paniagua, S., Kussmaul, S., and Rivier, F.: Geodinámica interna de Costa Rica, Rev. Geol. Amer. Central, 14, 1-12, 1992.

Mucher, C. A. and Badts, D. E. P. J.: Global Land Cover 2000: Evaluation of the SPOT VEGETATION sensor for land use mapping, Wageningen, Alterra, Green World Research, p. 49, 2002.

Munro, A.: Seeking storm surges, New Zealand Science Monthly, 10(11), 11, 1999.

OCHA: OCHA Situation Report n.2, web source: http: //www.reliefweb.int/rw/RWB.NSF/db900SID/SNAO-6GZSTG? OpenDocument, last access: 8 August 2008, 2005a.

OCHA: OCHA Situation Report n.3, web source: http://www. reliefweb.int/rw/RWB.NSF/db900SID/EVOD-6H3DTK? OpenDocument\&rc=2\&emid=TC-2005-000173-SLV, last access: 8 August 2008, 2005b.

O'Hare, G.: Hurricane 07B in the Godavari delta, Andhra Pradesh, India: vulnerability, mitigation and the spatial impact, The Geo- 
graphical Journal, 167(1), 23-38, 2001

Palmieri, S., Teodonico, L., Siani, A. M., and Casale, G. R.: Tropical storm impact in Central America, Meteorol. Appl., 13, 21-28, 2006.

Pasch, R. J. and Roberts, D. P.: Tropical Cyclone Report - Hurricane Stan, 1-5 October 2005, National Hurricane Center, web source: http://www.nhc.noaa.gov/2005atlan.shtml, last access: 8 August 2008, 2006.

Pender, G. and Neelz, S.: Use of computer models of flood inundation to facilitate communication in flood risk management, Environmental Hazards, 7(2), 106-114, 2007.

Penning-Rowsell, E. (Ed.): Improving Flood Hazard Management Across Europe, Middlesex University Press, London, 1996.

Penning-Rowsell, E. and Fordham, M. (Eds.): Floods across Europe, Flood Hazard Assessment, Modelling and Management, Middlesex University Press, London, 1994.

Pelupessy, W. (Ed.): Perspectives on the Agro-export Economy in Central America, Macmillan, Washington, 175 pp., 1991.

Pielke Jr., R. A., Rubeira, J., Landsea, C., Fernandez, M. L., and Klein, R.: Hurricane vulnerability in Latin America and the Caribbean: normalised damage and loss potentials, Natural Hazards Review, ASCE, Aug., 101-114, 2003.

Pielke Jr., R. A., Gratz, J., Landsea, C. W., Collins, D., Saunders, M. A., and Musulin, R.: Normalized Hurricane Damages in the United States: 1900-2005, Natural Hazards Review, 9(1), 29-42, 2008.

Puecker, T. K. and Douglas, D. H.: Detection of surface-specific points by local parallel processing of discrete terrain elevation data, Computer Graphics and Image Processing, 4, 375-387, 1975.

Riehl, H.: Tropical Meteorology, McGraw-Hill, 392 pp., 1954.

Russel, G. L., Miller, J. R., Rind, D., Ruedy, R. A., Schmidt, G. A., and Sheth, S.: Comparison of model and observed regional temperature changes during the past 40 years, J. Geophys. Res., 105(14), 891-898, 2000.

Saito, K., Spence, R. J. S., Going, C., and Markus, M.: Using highresolution satellite images for post-earthquake building damage assessment: a study following the 26 January 2001 Gujarat earthquake, Earthquake Spectra, 20, 1-25, 2004.

Sanyal J. and Lu, X. X.: Application of Remote Sensing in Flood Management with Special Reference to Monsoon Asia: A Review, Natural Hazards, 33(2), 283-301, 2004.

Saunders, M.: Global warming: the view in 1998, Benefield Greig Hazard Research Centre, University College-London, 120 pp. 1998.

Scheidegger, A. E.: Hazards: singularities in geomorphic systems, Geomorphology, 10, 19-25, 1994.

Schumann, D. A. and Partridge, W. L. (Eds.): The human ecology of tropical land settlement in Latin America. Westview Special Studies on Latin America and the Caribbean, Westview Press, Boulder Arizona, 470 pp., 1989.

Shen, B. W., Atlas, R., Reale, O., Lin, S. J., Chern, J. D., Chang, J., Henze, C., and Li, J. L.: Hurricane forecasts with a global mesoscale-resolving model: Preliminary results with Hurricane Katrina (2005), Geophys. Res. Lett., 33, L13813, doi:10.1029/2006GL026143, 2006.

Shipley, S. T.: GIS applications in meteorology, or adventures in a parallel universe. American Meteorological Society, BAMS Feb. 2005, 171-173, 2005.
Sorensen, J. H.: Hazard warning system: review of 20 years of progress, Natural Hazard Review, 1(2), 22139, 119-125, 2000.

Strahler, A. N.: System theory in general geography, Phys. Geogr., 1, 1-27, 1980.

Stramondo, S., Saroli, M., Tolomei, C., Moro, M., Doiumaz, F., Pesci, A., Loddo, F., Baldi, P., and Boschi, E.: Surface movements in Bologna (Po Plain-Italy) detected by multitemporal DInSAR, Remote Sens. Environ., 110, 304-316, 2007.

Taramelli, A. and Melelli, L.: Contribution of the Landsat ETM+ Spectral Mixing Space and SRTM analysis to characterize Deep Seated Gravitational Slope Deformations in central Apennines (Italy), Int. J. Remote Sens., in press, 2008.

Taramelli, A. and Melelli, L.: Strategy to delineate potentially affected areas by hurricane using GIS approach, Rend. Soc. Geol. It., 4, Nuova Serie, 27-34, 2007.

Taramelli, A. and Barbour, J.: A new DEM of Italy using SRTM data, Rivista Italiana Telerilevamento, 36, 3-15, 2006.

Tarboton, D. G.: A new method for the determination of flow directions and upslope areas in grid digital elevation models, Water Resour. Res., 33(2), 309-319, 1998.

Tarboton, D. G. and Ames, D. P.: Advances in the mapping of flow networks from digital elevation data. World Water and Environmental Resources Congress, 20-24 May, Orlando, Florida, 2001.

Taylor, G. I.: The instability of liquid surfaces when accelerated in a direction perpendicular to their planes, Proc. R. Soc. Lond. Ser. A., 201, 192-196, 1950.

Trenberth, K. E. and Shea, D. J.: Atlantic Hurricanes and Natural Variability in 2005, Geophys. Res. Lett., 33(12), L14703, doi:10.1029/2006GL026894, 2006.

Tucker, G. E., Catani, F., Rinaldo, A., and Bras, R. L.: Statistical analysys of drainage density from digital elevation data, Geomorphology, 36, 187-202, 2000.

UNEP-OCHA: Hurricane Stan: Environmental Impacts from Floods and Mudslides in Guatemala - Results from a rapid environmental assessment in Guatemala, http://ochaonline.un.org/ OchaLinkClick.aspx link=ocha\&DocId $=1003943$, last access: 11 August 2008, 2005.

Watson, C. C. and Johnson, M. E.: Hurricane loss estimation models, American Meteorological Society, BAMS - Nov. 2004, 1713-1726, 2005.

Webster, P. J, Holland, G. J., Curry, J. A., and Chang, H. R.: Changes in Tropical Cyclone Number, Duration and Intensity in a Warning Environment, Science, 309, 1844-1846, 2005.

World Bank: World Development Indicators, 1997, World Bank CD-ROM, World Bank, Washington, 1998.

Yuan, M.: Beyond Mapping in GIS applications to environmental analysis, American Meteorological Society, BAMS - Feb., 169170,2005

Xie, L., Bao, S., Pietrafesa, L. J., Foley, K., and Fuentesa, M.: RealTime Hurricane Surface Wind Forecasting Model: Formulation and Verification, Mon. Weather Rev., 134, 1355-1370, 2006.

Zenger, A. and Smith, D. I.: Impediments to using GIS for real-time disaster decision support, Computers, Environment and Urban Systems, 27(2), 123-141, 2003.

Zenger, A., Smith, D. I., Hunter, G. J., and Jones, S. D.: Riding the storm: a comparison of uncertainty modelling techniques for storm surge risk management, Appl. Geogr., 22(3), 307-330, 2002. 